\title{
Gastrointestinal Blood Flow and Oxygen Consumption in the Newborn Lamb: Effect of Chronic Anemia and Acute Hypoxia
}

\author{
PHILIP T. NOWICKI, NANCY B. HANSEN, WILLIAM OH, ${ }^{(34)}$ AND \\ BARBARA S. STONESTREET ${ }^{(32)}$ \\ The Department of Pediatrics, Women and Infants Hospital of Rhode Island, and the Program in Medicine, \\ Brown University, Providence, Rhode Island, USA
}

\begin{abstract}
Summary
The purpose of this study was to investigate the compensatory change in circulation and oxygenation of the newborn lamb gastrointestinal (GI) tract in response to anemic and hypoxic hypoxemia. Radiolabeled microspheres were used to measure blood flow. We subjected the newborn lamb to a 30-35\% reduction in hematocrit $4 \mathrm{~d}$ before study and to a $10 \%$ oxygen environment for $\mathbf{3 0} \mathrm{min}$ during the study to induce chronic anemic and acute hypoxic hypoxemia, respectively. The circulatory and oxygenation responses were measured $1 \mathrm{~h}$ after a standard milk feeding in all cases. During the experimental periods, no change in total GI blood flow was observed. Because of a failure to augment blood flow during hypoxemia, $\mathrm{O}_{2}$ delivery to the $\mathrm{GI}$ tract decreased significantly. Despite this, GI $\mathrm{O}_{2}$ consumption was not compromised because tissue $\mathrm{O}_{2}$ extraction by the GI tract rose significantly. The response of the newborn lamb GI tract to hypoxemia after feeding is augmentation of $\mathrm{O}_{2}$ extraction. The newborn's GI tract did not regulate local GI blood flow.
\end{abstract}

\section{Abbreviations}

$\mathrm{CaO}_{2}$, arterial oxygen content

$\mathrm{DO}_{2} \mathrm{GI}$, oxygen delivery to gastrointestinal tract

GI, gastrointestinal

$L V$, left ventricle

PV, portal vein

QGI, total gastrointestinal blood flow

$\mathrm{VO}_{2} \mathrm{GI}$, oxygen consumption by gastrointestinal tract

Hypoxemia can result from a decreased hemoglobin mass or diminished percentage saturation of hemoglobin. In each instance, hypoxemia will compromise tissue oxygenation unless adequate compensation occurs. The process of compensation can be mediated by increasing blood flow or tissue oxygen extraction. The compensatory response of the GI tract to hypoxemia has been evaluated in adult animals. Anemic hypoxemia resulted in decreased mesenteric vascular resistance and increased mesenteric blood flow in canine $(20,21,30)$ and feline (17) species. $\mathrm{O}_{2}$ extraction by the gut was unchanged; therefore, under these conditions, GI $\mathrm{O}_{2}$ consumption was maintained by regulating $\mathrm{O}_{2}$ delivery (17). In response to hypoxic hypoxemia, denervated dog small intestine demonstrated the capacity to increase local blood flow $(1,23)$ and enhance $\mathrm{O}_{2}$ extraction $(23)$.

The response of the newborn GI tract to hypoxemia has not been thoroughly investigated; however, previous work in the lamb suggests that the newborn's response to decreased $\mathrm{O}_{2}$ availability might differ from that of the adult. The lamb maintains a higher resting $\mathrm{O}_{2}$ consumption than mature sheep, which is affected by a high resting blood flow and low $\mathrm{O}_{2}$ extraction (7). When the oxidative demands of the lamb gut are increased by feeding, only a limited mesenteric hyperemia results whereas a significant and sustained rise in $\mathrm{O}_{2}$ extraction occurs (8). This response is unlike that found after feeding in adult animals, where large increases in mesenteric blood flow are observed (3, $5,27)$.

The purpose of this study was to investigate the compensatory changes occurring in the circulation and oxygenation of the newborn lamb GI tract in response to anemic or hypoxic hypoxemia. The response of the lamb GI tract was determined after the animals had eaten.

\section{MATERIALS AND METHODS}

Preparation of Animals. Fifteen 3-d-old newborn lambs were catheterized under ketamine $(10 \mathrm{mg} / \mathrm{kg}$ intramuscular) and $x y-$ locaine ( $1 / 2 \%$, subcutaneous) anesthesia. Polyvinyl catheters (outerdiameter, 70; inner diameter, 40) were placed in the LV via the left carotid artery, PV via the common umbilical vein, and abdominal aorta just distal to the celiac axis, via the left femoral artery. The position of the LV catheter was verified by pressure tracing. All catheters were filled with heparin $(1000 \mu / \mathrm{ml})$ and tunnelled subcutaneously to a gauze pouch on the animal's flank. The animals received three doses of ampicillin $(100 \mathrm{mg} / \mathrm{kg})$ and kanamycin $(5 \mathrm{mg} / \mathrm{kg})$ on the first postoperative day.

The PV catheter was used to measure $\mathrm{O}_{2}$ content of the venous drainage from the GI tract, and thus to calculate total $\mathrm{GI} \mathrm{O}_{2}$ extraction and consumption. Previous work in lambs had demonstrated the efficacy of sampling portal vein $\mathrm{O}_{2}$ content using a catheter advanced through the common umbilical vein $(7,8)$. In the present study, the tip of the PV catheter was at or near the bifurcation of the PV in all instances.

Experimental Protocol. On the second postoperative day, the animals were randomly divided into normal $(n=7)$ had anemia $(n=8)$ groups. Each animal in the anemia group had a total of $30 \mathrm{ml} / \mathrm{kg}$ of whole blood removed, which was accomplished by performing three separate phlebotomies of $10 \mathrm{ml} / \mathrm{kg}$ each over a $24 \mathrm{~h}$ period. The last phlebotomy occurred $48 \mathrm{~h}$ or more before the onset of blood flow measurements. This degree of phlebotomy was chosen to produce a decrease in hematocrit of approximately $30-35 \%$, thus inducing a moderate anemia for this species. The normal group underwent routine catheter flushing during this period.

All animals recovered from surgery and maintained stable hematocrits on the first postoperative day. Those animals who underwent phlebotomy displayed no outward ill effects from the procedure and all animals fed normally and gained weight. 
During the time between surgery and blood flow measurement, the lambs were housed in pens with the ewe. Twelve hours before the onset of measurements, the lambs were removed to separate cages where they had no access to milk or water.

On the fifth postoperative day, the animals were brought to the laboratory and placed in a large cardboard box of sufficient size to allow the animals to lie comfortably. The box was open only at the top and the animals were left as undisturbed as possible. A series of four blood flow, hematocrit, arterial blood gas, and arteriovenous $\mathrm{O}_{2}$ content measurements were made on each animal. The first preprandial baseline measurement was taken. The first feeding was then administered, consisting of 150 $\mathrm{ml}$ of $1: 1$ dilution (with water) whole cow's milk given over 5 min through an oro-gastric gavage tube. Sixty minutes later the first postprandial measurement was obtained. The animal was left undisturbed for $3 \mathrm{~h}$. After this resting period, a second preprandial baseline measurement was taken. A second feeding was then given, identical in content to the first, and 30 min later the head placed in a clear plastic bag. Compressed air $(10 \mathrm{~L} /$ min) and a balance gas of $5 \% \mathrm{CO}_{2} 95 \% \mathrm{~N}_{2}$ were passed into the bag resulting in an $\mathrm{FiO}_{2}$ of 0.1 . Thirty minutes after the induction of hypoxia, and $60 \mathrm{~min}$ after the second feeding, the postprandial hypoxia measurement was obtained. The animals was then sacrificed by pentobarbital overdose.

The response of the GI tract to stress (e.g., altered perfusion pressure, hypoxemia) may, in part, depend on the pre-existing functional state of the tissue (19). To eliminate variation in this regard, the effect of hypoxemia was determined $1 \mathrm{~h}$ after a standard feeding challenge in all instances. The duration of fasting which preceded the two feedings differed in the following manner: the first feeding was given after a 12 -h overnight fast whereas the second feeding was given only $4 \mathrm{~h}$ after the first feeding had been administered. Previous studies in lambs have shown that the duration of fasting has little effect on the postprandial response of the GI tract $(7,8)$ and, thus, this temporal discrepancy was not considered significant. In addition, the postprandial response of the lamb is of short duration (8) so that blood flow and oxygenation parameters return to preprandial levels within $3 \mathrm{~h}$ after feeding. In the present study, a measurement was taken just before the second feeding to allow documentation that all blood flow and oxygenation parameters had indeed returned to the preprandial baseline values.

GI blood flow was measured with microspheres, $15 \pm 5 \mu$ diameter, labeled with one of six radionuclides: $\left[{ }^{5} \mathrm{Cr}\right],\left[{ }^{113} \mathrm{Sn}\right]$, $\left[{ }^{46} \mathrm{Sc}\right],\left[{ }^{95} \mathrm{Nb}\right],\left[{ }^{57} \mathrm{Co}\right],\left[{ }^{103} \mathrm{Ru}\right]$ (New England Nuclear Inc., Boston, MA). Approximately $1.2 \times 10^{6}$ microspheres suspended in $3 \mathrm{ml}$ of $10 \%$ dextran were continuously agitated and injected into the LV over $30 \mathrm{sec}$, and the microspheres flushed wtih $2 \mathrm{ml} 0.9 \%$ $\mathrm{NaCl}$. A reference arterial blood sample was withdrawn from the aortic catheter at a constant flow rate of $4.08 \mathrm{ml} / \mathrm{min}$, beginning $10 \mathrm{sec}$ before microsphere injection, and lasting for $120 \mathrm{sec}$. Each reference blood sample contained at least 1000 microspheres and each tissue segment more than 400 microspheres (12).

Arterial blood gases were measured using a Corning Blood Gas Analyzer 165 (Corning Scientific, Medford, MA) and $\mathrm{O}_{2}$ contents measured in duplicate with a Lex- $\mathrm{O}_{2}$-Con (Lexington Instruments, Waltham, MA). Heart rate and systemic arterial blood pressure were measured before and after each microsphere injection using a Bentley Trantec Transducer (Bentley Laboratory, Inc., Irving, CA) and recorded on a Hewlett-Packard Polygraph (7700 series, Lexington, MA).

Tissue Preparation. The position of all catheters was verified at autopsy. The GI tract was removed and separated into stomach, jejunum, ileum, and colon. For this study, jejunum was considered the proximal half of the small intestine, and ileum the distal half. The entire GI tract [weighing $233 \pm 42$ and 224 $\pm 33 \mathrm{~g}$ (mean \pm SEM) for normal and anemic groups, respectively] was washed, and fixed in a $10 \%$ formalin solution for at least $24 \mathrm{~h}$. Subsequently, the stomach and colon were carbonized at $275^{\circ} \mathrm{C}$ for $72 \mathrm{~h}$, and the resultant ash uniformly packed to 1 $\mathrm{cm}$ height in plastic counting vials. The ileum and jejunum were further dissected into villous-submucosa and muscularis-serosa layers, using a blunt dissection method previously described (2). Routine histologic evaluation of tissue prepared in this fashion disclosed an accurate separation. Previous work has verified the utility and reliability of using $15-\mu$ microspheres in determining blood flow to the muscularis-serosa and mucosa-submucosa layers of the small intestinal wall. Technical difficulty has ensued when microspheres have been used to fractionate mucosa and submucosal layers $(2,18)$; however, in this study, these tissues were grouped as one layer. This tissue was also uniformly packed to $1 \mathrm{~cm}$ height in plastic counting vials. Radioactivity from the blood and tissue specimens was measured in a well-type gamma spectrometer (Packard Autogamma Scintillation Spectrometer, Packard Instruments, Downer Grove, IL). Blood flow data were obtained using a computer which corrected for isotope decays and spillover (PdP-11/34 Digital Equipment Corp., Maynard, $\mathrm{MA}$ ), and calculated flows using the following equation (12):

Tissue blood flow

$$
\begin{aligned}
& =\frac{\text { cpm tissue }}{\text { cpm reference }} \\
& \text { blood sample } \\
& \times \text { rate of withdrawal of reference sample }
\end{aligned}
$$

Data Calculation and Analysis. $\mathrm{O}_{2}$ delivery and $\mathrm{O}_{2}$ consumption data were obtained using derivations of the Fick principle:

$\mathrm{O}_{2}$ delivery $\left(\mathrm{DO}_{2}\right)=(\mathrm{Q}) \times \operatorname{arterial}\left(\mathrm{O}_{2}\right.$ content $\left.\left[\mathrm{CaO}_{2}\right]\right)$

$\mathrm{O}_{2}$ consumption $\left(\mathrm{VO}_{2}\right)=(\mathrm{Q}) \times\left(\mathrm{CaO}_{2}\right.$ - portal venous $\mathrm{O}_{2}$ content $\left[\mathrm{C}_{\mathrm{pv}} \mathrm{O}_{2}\right]$ )

$\mathrm{O}_{2}$ extraction $=\mathrm{VO}_{2} / \mathrm{DO}_{2}=\mathrm{CaO}_{2}-\mathrm{CvO}_{2} / \mathrm{CaO}_{2}$

Blood flow is expressed in $\mathrm{ml} \cdot \mathrm{min}^{-1} \cdot \mathrm{kg}^{-1}$ body weight and $\mathrm{DO}_{2}$ and $\mathrm{VO}_{2}$ are expressed in $\mathrm{ml} \mathrm{O}_{2} \cdot \mathrm{min}^{-1} \cdot \mathrm{kg}^{-1}$ body weight.

A blocked one-way analysis of variance and Dunnett's test were used to analyze sequential changes occurring in each group. Unpaired $t$ tests were used to compare data between groups, and the Bonferroni method (31) used to correct for multiple $t$ test analysis. The study design allowed observation of the response of the lamb GI tract circulation and oxygenation to four distinct circumstances. Three distinct modes and degrees of hypoxemia were induced, and the GI tract response to them observed while the animal was in the postprandial state. In the normal group, comparison of the first postprandial to first preprandial measurement demonstrated the effect of cow milk gavage feeding and this established the normative postprandial response in our experimental model. The same two measurement periods in the anemia group showed the response to the combined effect of anemic hypoxemia and feeding. In the normal group, comparison of the postprandial-hypoxia measurement with the second preprandial baseline revealed the response to the combined effect of hypoxic hypoxemia and feeding. Finally, this second set of measurements in the anemia groups demonstrated the response to hypoxia superimposed on anemia in the postprandial state.

\section{RESULTS}

Table 1 shows that the age, body weight, and initial hematocrit data were similar in both groups. After phlebotomy, the anemic group showed a hematocrit of $20.5 \pm 0.6 \%$, which was lower $(P$ $<0.05)$ than the normal group. Table 2 lists arterial $\mathrm{O}_{2}$ content and $\mathrm{PaO}_{2}$ values, and shows that the anemic group maintained a lower $\mathrm{CaO}_{2}(P<0.05)$ than the normal group, despite similar $\mathrm{PaO}_{2}$ values. During acute hypoxia, both groups showed a $25-$ $30 \%$ decrease in $\mathrm{PaO}_{2}$ and $\mathrm{CaO}_{2}$ compared with the second preprandial measurement. As a result, the degree of hypoxemia observed in the anemia group was greater than the normal group $(P<0.05)$. The initial pH and $\mathrm{PaCO}_{2}$ of both groups were similar (normal 7.38 $\pm 0.03,30.5 \pm 1.5 \mathrm{~mm} \mathrm{Hg}$; anemia, $7.41 \pm 0.02$, $29.8 \pm 2.1 \mathrm{~mm}$ Hg; mean \pm SEM) and did not change significantly at any time during the study. Similarly, no significant 
change in blood pressure, pulse, or respiratory rate occurred as a result of microsphere injection. Neither group showed a significant difference in these parameters at any time during the study. With hypoxia, both groups demonstrated an increased pulse and respiratory rate whereas blood pressure remained unchanged (data not shown).

Table 3 shows QGI, $\mathrm{DO}_{2} \mathrm{GI}, \mathrm{O}_{2}$ extraction, and $\mathrm{VO}_{2} \mathrm{GI}$ for both groups. Values obtained for these parameters during the two preprandial baseline measurements were statistically similar, demonstrating that the animals had returned to initial preprandial levels before the second feeding. There was no major postprandial response noted in the normal group after the first feeding. $\mathrm{DO}_{2} \mathrm{GI}$ and $\mathrm{O}_{2}$ extraction did increase slightly, but the changes were not statistically significant. $\mathrm{VO}_{2} \mathrm{GI}$ remained near the preprandial level. The feeding stimulus employed in this study, therefore, did not alter GI circulation and oxygenation to a significant degree.

The compensatory response of the lamb GI tract to the combined effect of feeding and hypoxemia was similar regardless of the method by which hypoxemia was induced. Anemic hypox-

Table 1. Age, body weight, and hematocrit (Hct) values*

\begin{tabular}{ccccc}
\hline & $\begin{array}{c}\text { Age } \\
(\mathrm{d})\end{array}$ & $\begin{array}{c}\text { Body } \\
\text { weight } \\
(\mathrm{kg})\end{array}$ & $\begin{array}{c}\mathrm{Hct} \\
(\%) \\
(\text { study d 1) }\end{array}$ & $\begin{array}{c}\text { Hct (\%) } \\
\text { (study d 5) }\end{array}$ \\
\hline $\begin{array}{c}\text { Normal } \\
(n=7)\end{array}$ & $8.3 \pm 0.4$ & $4.7 \pm 0.2$ & $31.0 \pm 1.2$ & $31.3 \pm 1.4$ \\
$\begin{array}{c}\text { Anemia } \\
(n=8)\end{array}$ & $8.1 \pm 0.3$ & $4.6 \pm 0.3$ & $30.6 \pm 1.0$ & $20.5 \pm 0.6 \dagger$ \\
\hline
\end{tabular}

$*$ Mean \pm SEM.

$\uparrow P<0.025$ vs normal. emia and feeding had no effect on QGI; thus, $\mathrm{DO}_{2} \mathrm{GI}$ decreased $(P<0.05)$ due to the lower $\mathrm{CaO}_{2}$ of the anemic animals. $\mathrm{O}_{2}$ extraction increased by $33 \pm 3 \%(P<0.05)$ and $\mathrm{VO}_{2}$ GI was not comprised. A similar pattern was observed after hypoxic hypoxemia and feeding: QGI remained unchanged and $\mathrm{DO}_{2}$ GI consequently declined $(P<0.05)$. In this instance, however, the increase in $\mathrm{O}_{2}$ extraction was not significant. The degree of hypoxemia induced during acute hypoxia in the normal group was mild, and it is possible that only minor compensation was necessary to maintain $\mathrm{VO}_{2} \mathrm{GI}$. Acute hypoxia superimposed on chronic anemia resulted in the most severe degree of hypoxemia, but once again the combined effect of this hypoxemia and feeding did not alter QGI. $\mathrm{DO}_{2} \mathrm{GI}$, thus, decreased significantly $(P<$ $0.05) . \mathrm{O}_{2}$ extraction increased by $79 \pm 4 \%(P<0.05)$ to maintain $\mathrm{VO}_{2} \mathrm{GI}$.

The effect of hypoxemia and feeding on regional GI blood flow to the stomach, jejunum, ileum, and colon is illustrated in Figure 1. In the normal group, feeding resulted in no change in regional GI blood flow. The effect of feeding and anemia or hypoxic hypoxemia on regional GI blood flow was similar, as in neither case was any significant change demonstrated. During the more severe degree of hypoxemia induced when anemia and hypoxia were superimposed, blood flow to the stomach decreased $(P<0.05)$.

Table 4 presents blood flow to the muscularis and mucosa layers of the jejunum and ileum. The mucosa consistently received a greater blood flow than the muscularis layer. In the normal group, the first feeding did not change blood flow to either layer, and a similar observation was made after the first feeding in the anemia group. The postprandial-hypoxia measurement, however, demonstrated an increase in muscularis layer blood flow in both groups. Both hypoxic hypoxemia and hypoxia superimposed on anemia produced a similar change. Blood flow to the mucosa layer did not change at this time.

Table 2. Arterial $\mathrm{O}_{2}$ content and $\mathrm{PaO}_{2}$ values*

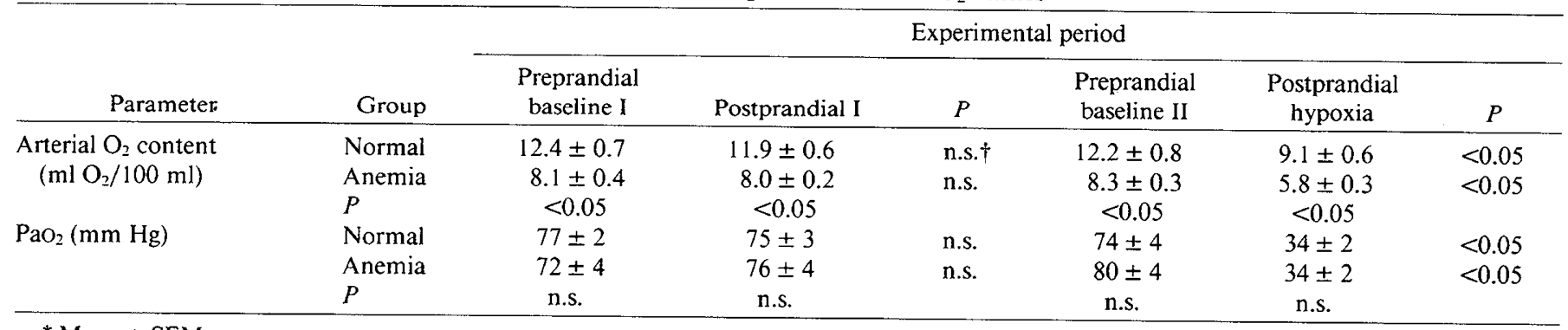

$*$ Mean \pm SEM.

$\dagger$ n.s., not significant.

Table 3. Total GI blood flow, $\mathrm{O}_{2}$ delivery, $\mathrm{O}_{2}$ extraction, and $\mathrm{O}_{2}$ consumption*

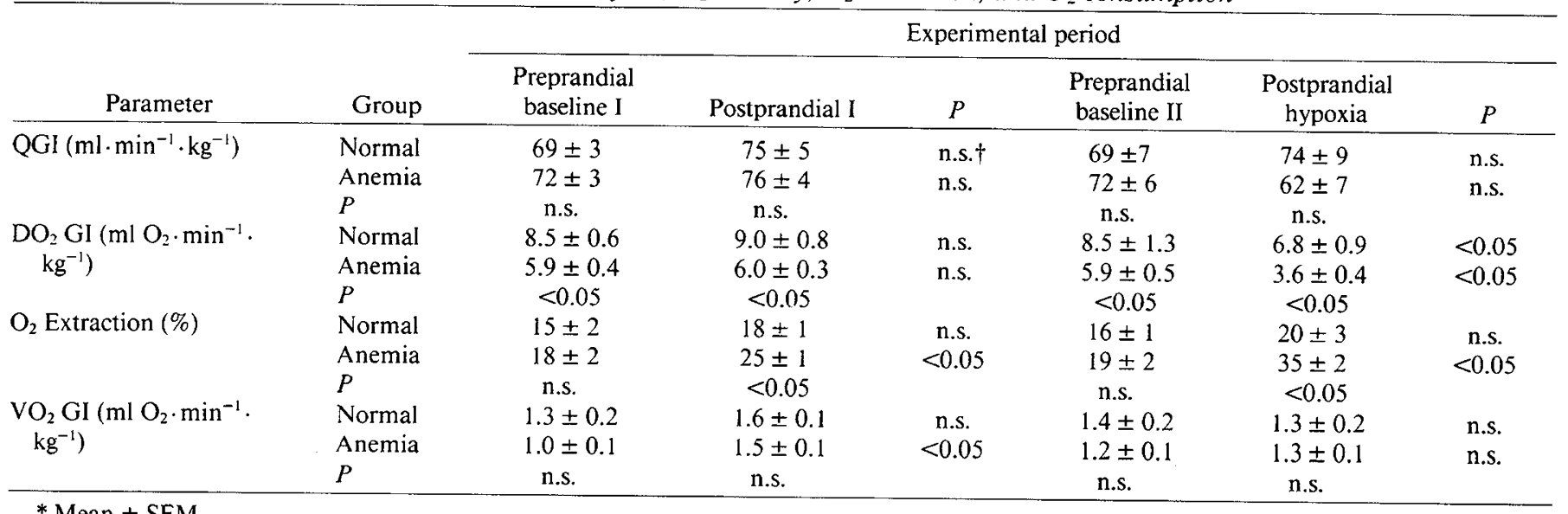

\footnotetext{
$*$ Mean \pm SEM.
}

$\dagger$ n.s., not significant. 


\section{DISCUSSION}

The method employed to determine $\mathrm{VO}_{2} \mathrm{GI}$ and $\mathrm{O}_{2}$ extraction measured the summed response of the whole GI tract. This was somewhat disadvantageous, as subtle regional changes might have been lost in the large mass of tissue being sampled, and the capacity to ascertain specific regional differences in $\mathrm{VO}_{2}$ or $\mathrm{O}_{2}$ extraction did not exist. In addition, the spleen, pancreas, and mesentery drain via the portal vein introduced a small error in the calculation of GI tract oxygenation (7). Data from this study must be viewed in light of these limitations. The advantage gained by this technique was 2 -fold: 1 ) minimal instrumentation of the abdominal vasculature was necessary, and 2) the animal could be studied in the awake, intact state.

In this study, the effect of hypoxemia was studied when the GI tract was in the postprandial state. Previous work in the lamb demonstrated that the oxidative demands of the GI tract increase after feeding, and that this effect is maximal $1 \mathrm{~h}$ after the meal is taken (8). Our study design took this into consideration, so that postprandial measurements were made $1 \mathrm{~h}$ after feeding.

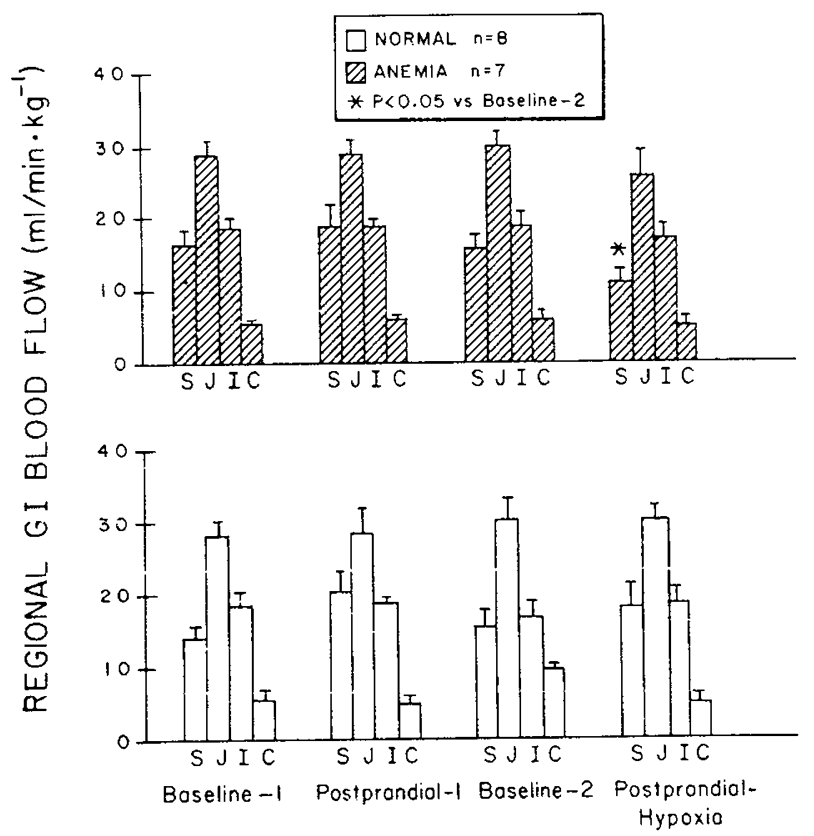

Fig. 1. Regional GI blood flow (S, stomach; J, jejunum; I, ileum; and C, colon).
We measured the response to decreased $\mathrm{O}_{2}$ availability (hypoxemia) at the same time that the oxidative demands of the GI tract had been increased (feeding). The results, thus, reflect the combined effect of these two stimuli. It is possible that the response of the fasted, preprandial GI tract to similar degrees of hypoxemia might differ from that reported here. The distinct responses of the fed versus fasted GI tract was previously demonstrated in the adult dog, where autoregulation during hypotension was more effective after feeding (19).

The total and regional GI tract blood flows, $\mathrm{DO}_{2} \mathrm{GI}, \mathrm{O}_{2}$ extraction, and $\mathrm{VO}_{2} \mathrm{GI}$ data obtained for the normal group during the first preprandial measurement are similar to data previously obtained in the newborn lamb $(7,8)$. The response of the GI tract to the first feeding, however, differed from that previously reported in the lamb (8). In their study, Edelstone and Holzman (8) demonstrated a $23 \%$ increase in QGI, and a larger more sustained increase in $\mathrm{O}_{2}$ extraction such that $\mathrm{VO}_{2} \mathrm{GI}$ significantly increased for several hours after feeding. Control animals in this study demonstrated a $24 \pm 4 \%$ increase in $\mathrm{VO}_{2} \mathrm{GI}$ and $12 \pm 1 \%$ rise in $\mathrm{O}_{2}$ extraction; however, these changes failed to attain statistical significance. Differences in experimental design, specifically the manner by which feeding was accomplished, might account for this discrepancy. In their study, Edelstone and Holzman (8) allowed the lambs to nurse naturally, whereas our lambs were gavage fed with dilute cow's milk. Previous work has indicated that the composition of a meal affects postprandial blood flow changes (27); furthermore, gavage feeding bypasses the anticipatory stage of digestion, which could alter postprandial blood flow changes (11).

Chronic anemic hypoxemia did not cause any significant change in total or regional QGI $1 \mathrm{~h}$ after feeding, so that $\mathrm{DO}_{2} \mathrm{GI}$ was decreased in the anemic animals. These findings are not entirely consistent with previous studies. The effects of both isovolemic hemodilution $(17,20,21)$ and chronic anemia (13, 30 ) on GI blood flow have been studied using adult dogs. Isovolemic hemodilution (decrease in hematocrit by $20-35 \%$ ) resulted in a decrease in mesenteric vascular resistance and an increase in GI blood flow $(17,20,21)$. Chronic anemia induced by repeated phlebotomy caused no change in mesenteric blood flow when hematocrit was reduced by $30 \%(13,30)$. When more severe anemia was produced (hematocrit, 14-16\%), mesenteric blood flow increased. In the present study, the hematocrit was decreased by $33 \pm 2 \%$, producing only a moderate degree of anemia for this species. It remains possible that more substantial reduction in hematocrit might alter mesenteric blood flow in the lamb.

Acute hypoxic hypoxemia in the postprandial state caused no change in total QGI; hence, as was the case for anemic hypox-

Table 4. Blood flow to the muscularis and mucosa layers of ileum and jejunum*

\begin{tabular}{|c|c|c|c|c|c|c|c|}
\hline \multirow[b]{2}{*}{ Parameter } & \multirow[b]{2}{*}{ Group } & \multicolumn{6}{|c|}{ Experimental condition } \\
\hline & & $\begin{array}{c}\text { Preprandial } \\
\text { baseline I }\end{array}$ & Postprandial I & $P$ & $\begin{array}{c}\text { Preprandial } \\
\text { baseline II }\end{array}$ & $\begin{array}{c}\text { Postprandial } \\
\text { hypoxia }\end{array}$ & $P$ \\
\hline Jejunum muscularis & Normal & $1.4 \pm 0.4$ & $1.9 \pm 0.3$ & n.s. $\dagger$ & $1.9 \pm 0.4$ & $2.3 \pm 0.8$ & n.s. \\
\hline$\left(\mathrm{ml} \cdot \mathrm{min}^{-1} \cdot \mathrm{kg}^{-1}\right)$ & $\begin{array}{l}\text { Anemia } \\
P\end{array}$ & $\begin{array}{c}1.9 \pm 0.4 \\
\text { n.s. }\end{array}$ & $\begin{array}{c}1.5 \pm 0.3 \\
\text { n.s. }\end{array}$ & n.s. & $\begin{array}{c}1.6 \pm 0.3 \\
\text { n.s. }\end{array}$ & $\begin{array}{l}2.1 \pm 0.4 \\
\text { n.s. }\end{array}$ & n.s. \\
\hline Jejunum mucosa & Normal & $26.3 \pm 1.9$ & $27.8 \pm 2.2$ & n.s. & $28.8 \pm 2.7$ & $23.5 \pm 3.7$ & n.s. \\
\hline$\left(\mathrm{ml} \cdot \mathrm{min}^{-1} \cdot \mathrm{kg}^{-1}\right)$ & $\begin{array}{l}\text { Anemia } \\
P\end{array}$ & $\begin{array}{c}28.1 \pm 1.8 \\
\text { n.s. }\end{array}$ & $\begin{array}{c}29.7 \pm 1.2 \\
\text { n.s. }\end{array}$ & n.s. & $\begin{array}{c}28.5 \pm 3.1 \\
\text { n.s. }\end{array}$ & $\begin{array}{c}30.1 \pm 2.7 \\
\text { n.s. }\end{array}$ & n.s. \\
\hline Ileum muscularis & Normal & $2.1 \pm 0.4$ & $2.2 \pm 0.3$ & n.s. & $2.5 \pm 0.7$ & $3.3 \pm 0.7$ & $<0.05$ \\
\hline$\left(\mathrm{ml} \cdot \min ^{-1} \cdot \mathrm{kg}^{-1}\right)$ & $\begin{array}{l}\text { Anemia } \\
P\end{array}$ & $\begin{array}{c}2.5 \pm 0.3 \\
\text { n.s. }\end{array}$ & $\begin{array}{c}2.2 \pm 0.4 \\
\text { n.s. }\end{array}$ & n.s. & $\begin{array}{c}2.3 \pm 0.4 \\
\text { n.s. }\end{array}$ & $\begin{array}{c}3.3 \pm 0.5 \\
\text { n.s. }\end{array}$ & $<0.05$ \\
\hline Ileum mucosa & Normal & $14.8 \pm 0.5$ & $16.0 \pm 0.9$ & n.s. & $16.0 \pm 1.4$ & $12.8 \pm 1.9$ & n.s. \\
\hline$\left(\mathrm{ml} \cdot \mathrm{min}^{-1} \cdot \mathrm{kg}^{-1}\right)$ & $\begin{array}{l}\text { Anemia } \\
P\end{array}$ & $\begin{array}{c}14.2 \pm 0.8 \\
\text { n.s. }\end{array}$ & $\begin{array}{c}15.1 \pm 0.8 \\
\text { n.s. }\end{array}$ & n.s. & $\begin{array}{c}13.4 \pm 1.9 \\
\text { n.s. }\end{array}$ & $\begin{array}{c}15.3 \pm 2.3 \\
\text { n.s. }\end{array}$ & n.s. \\
\hline
\end{tabular}

* Mean \pm SEM.

$\dagger$ n.s., not significant. 
emia, $\mathrm{DO}_{2} \mathrm{GI}$ fell. Previous investigations have suggested that hypoxic hypoxemia results in a vasodilation of mesenteric vessels, leading to an increased blood flow to the small intestine (1, $23,25,29)$. These studies, performed in adult feline (29) and canine $(1,23,25)$ animals, employed denervated, isolated intestinal loop preparations, which in some cases were artificially perfused. In the present study, all neural pathways remained intact and the animals were awake; hence, our data are not directly comparable with these studies. In an intact fetal lamb preparation, acute moderate hypoxic hypoxemia resulted in no change in small intestinal blood flow (9), an observation consistent with our findings. Edelstone and Holzman (7) have speculated that the mesenteric vasculature of the lamb exists in a maximal vasodilated state, so that changes in $\mathrm{O}_{2}$ availability or demand cannot be met by increases in blood flow. Our data indicate that total GI tract blood flow does not increase during hypoxemia, and thus supports this concept.

During the postprandial-hypoxia measurement, regional changes were observed in blood flow to the stomach and within the wall of the ileum, suggesting that some responsiveness to vasoactive stimuli does exist. Previous work has indicated that different portions of the GI tract maintain different capacities to alter blood flow during hypoxemia or decreased perfusion pressure: the stomach (4) and colon (16) display a limited ability to augment blood flow whereas the intestine (10) showed a greater capacity to do so. The present data reveal that blood flow to the stomach decreased in the anemic animals during the $1 \mathrm{hr}$ postprandial with hypoxia measurement; Edelstone and Holzman (8) have demonstrated that postprandial blood flow increases are primarily localized to the stomach. This suggests that in the lamb, the vascular supply to the stomach might be most responsive to local or central vasoactive stimulation. Alternatively, this could indicate that the lamb stomach is less able to vary $\mathrm{O}_{2}$ extraction, therefore relying more heavily on control of oxygen delivery to maintain oxygenation.

The increase in muscularis layer blood flow in the ileum wall was observed only during hypoxic hypoxemia. The reasons for this change are not certain. The level of circulating catecholamines abruptly increased during hypoxia in fetal and newborn lambs (6). Epinephrine and norepinephrine are known effectors in mesenteric vascular tone $(14,26,28)$, and have been implicated in redistribution of flow within the wall of the small intestine $(14,26)$. We did not measure catecholamine levels in the present study, and the direct effect of epinephrine and norepinephrine on the neonatal GI tract remains to be evaluated, so that the role of catecholamines in affecting the regional blood flow changes remains speculative. Of interest is that blood flow to the mucosa layer did not change during this measurement, suggesting that selective mucosal ischemia does not occur in proportion to the degree of induced hypoxemia.

Despite the fall in $\mathrm{DO}_{2} \mathrm{GI}$ observed during hypoxemia, $\mathrm{VO}_{2} \mathrm{GI}$ was not compromised by the degree of anemia or hypoxia achieved. The response to a decrease in the $\mathrm{O}_{2}$ availability-todemand ratio was a significant increase in $\mathrm{O}_{2}$ extraction by the GI tract. The degree of increase in $\mathrm{O}_{2}$ extraction matched the level of hypoxemia and, therefore, the degree of decrease in $\mathrm{DO}_{2} \mathrm{GI}$. The largest increase in $\mathrm{O}_{2}$ extraction occurred during the most severe hypoxemia whereas the least increase was observed during the mildest hypoxemia. This response is consistent with previous observations in the newborn and fetal (9) lamb: in response to feeding (increased $\mathrm{O}_{2}$ demand) or arterial hypoxemia (decreased $\left.\mathrm{DO}_{2} \mathrm{GI}\right), \mathrm{O}_{2}$ extraction rose significantly. Studies on the microvascular control of tissue oxygenation in the intestine have suggested that the response of the tissue to a change in the $\mathrm{O}_{2}$ availability-to-demand ratio is dependent on the pre-existing state of the tissue (10). If $\mathrm{O}_{2}$ availability-to-demand ratio is high, and $\mathrm{O}_{2}$ extraction levels low, then the principal response to a decrease in that ratio is to enhance $\mathrm{O}_{2}$ extraction, rather than augment $\mathrm{O}_{2}$ delivery. These conditions exist in the newborn lamb and, therefore, predict the observed increase in $\mathrm{O}_{2}$ extrac- tion during hypoxemia. Increasing evidence suggests that the GI tract maintains tissue oxygenation pricipally by altering the level of $\mathrm{O}_{2}$ extraction via capillary recruitment (24). $\mathrm{VO}_{2} \mathrm{GI}$ does not appear dependent on blood flow (and hence $\mathrm{DO}_{2} \mathrm{GI}$ ) until blood flow falls significantly (15). Our data indicate that the newborn lamb behaves in a similar fashion, relying primarily on changes in $\mathrm{O}_{2}$ extraction in response to a decreased $\mathrm{O}_{2}$ availability-todemand ratio.

This response to hypoxemia is consistent with the metabolic model of local circulatory control (22). This concept suggests that blood flow is not the prime variable manipulated by local regulatory activity, but rather that tissue oxygenation is the controlled variable. In an effort to maintain tissue oxygenation, a change in arteriolar resistance vessels and, hence, blood flowor change in capillary density and, hence, $\mathrm{O}_{2}$ extraction-can occur (22).

The newborn lamb gut demonstrated an adequate compensatory response to moderate arterial hypoxemia. Although no capacity to regulate QGI was observed, sufficient regulation of tissue $\mathrm{O}_{2}$ extraction occurred to maintain $\mathrm{VO}_{2} \mathrm{GI}$ during periods of decreased $\mathrm{O}_{2}$ availability. The responses to hypoxemia induced by anemia or hypoxia were qualitatively and quantitatively similar. It remains unresolved at what level of anemic or hypoxic hypoxemia $\mathrm{VO}_{2} \mathrm{GI}$ would become compromised.

\section{REFERENCES AND NOTES}

1. Bean, J. and Sidky, M.: Effects of low $\mathrm{O}_{2}$ on intestinal blood flow, tonus, and motility. Am. J. Physiol., 189: 541 (1957).

2. Bond, J. and Levitt, M.: Use of microspheres to measure small intestinal villus blood flow in the dog. Am. J. Physiol., 5: E577 (1979).

3. Bond, J., Prentiss, R., and Levitt. M.: The effects of feeding on blood flow to the stomach. small bowel, and colon of the conscious dog. J. Lab. Clin. Med., 93: 594 (1979)

4. Bowen, J. and Garg, D.: Effect of graded mechanical ischemia on oxygen tension and electrical potential in the canine gastric mucosa. Gastroenterology, 73: 84 (1977).

5. Chou, C., Hsieh, C., Yu, Y., Kvietys, P., Yu, L., Pittman, R., and Dabney, J.: Localization of mesenteric hyperemia during digestion in dogs. Am. J. Physiol., 230: 583 (1976)

6. Cohen, W., Paisecki, G., and Jackson, B.: Plasma catecholamines during hypoxemia in fetal lambs. Am. J. Physiol., 243: R520 (1982).

7. Edelstone, D. and Holzman, 1.: Oxygen consumption by the gastrointestinal tract and liver in conscious newborn lambs. Am. J. Physiol., 246: G297 (1981).

8. Edelstone, D. and Holzman, I.: Gastrointestinal tract $\mathrm{O}_{2}$ uptake and regional blood flows during digestion in conscious newborn lambs. Am. J. Physiol., 241: G289 (1981)

9. Edelstone, D. and Holzman, I.: Fetal intestinal oxygen consumption at various levels of oxygenation. Am. J. Physiol., 242: H50 (1982).

10. Granger, H. and Norris, C.: Intrinsic regulation of intestinal oxygenation in the anesthetized dog. Am. J. Physiol., 238: H836 (1980).

11. Granger, D., Richardson, D., Kvietys, P., and Mortillaro, N.: Intestinal blood flow. Gastroenterology, $78: 837$ (1980).

12. Heymann, M., Payne, B., Hoffman, J., and Rudolph, A.: Blood flow measurements with radionuclide-labelled particles. Prog. Cardiovasc. Dis., 20: 55 (1977).

13. Hoffbrand, B. and Forsyth, R.: The hemodynamic consequences of moderate postoperative anemia in monkeys. Surg. Gynecol. Obst., 132: 61 (1971).

14. Hulten, L., Lindhagen, J., and Lundgren, O.: Sympathetic nervous control of intramural blood flow in the feline and human intestines. Gastroenterology, 72: 41 (1977).

15. Kvietys, P. and Granger, D.: Relation between intestinal blood flow and oxygen uptake. Am. J. Physiol., 242: G202 (1980).

16. Kvietys, P., Miller, T., and Granger, D.: Intrinsic control of colonic blood flow and oxygenation. Am. J. Physiol., 238: G478 (1980).

17. Lautt. W.: Control of hepatic and intestinal blood flow. J. Physiol., 265: 313 (1977).

18. Maxwell, L., Shepherd, A., Riedel, G., and Morris, M.: Effect of microsphere size on apparent intramural distribution of intestinal blood flow. Am. J. Physiol., 241: H408 (1981).

19. Norris, C. P., Barnes, G., Smith, E., and Granger, H. J.: Autoregulation of superior mesenteric flow in fed and fasted dogs. Am. J. Physiol., 237: H174 (1979).

20. Race, D., Dedichen, H., and Schenk, W.: Regional blood flow during dextran induced normovolemic hemodilution in the dog. J. Thoracic Cardiovasc.
Surg., 48: 578 (1967).

21. Rosberg, B. and Wulff, K.: Regional blood flow in normovolaemic and hypovolaemic haemodilution. Br. J. Anesth., 51: 423 (1979).

22. Shepherd, A.: Local control of intestinal oxygenation and blood flow. Ann. Rev. Physiol., 44: 13 (1982). 
23. Shepherd, A.: Intestinal $\mathrm{O}_{2}$ consumption and ${ }^{86} \mathrm{Rb}$ extraction during arterial hypoxia. Am. J. Physiol., 234: E248 (1978).

24. Shepherd, A.: Role of capillary recruitment on the regulation of intestinal oxygenation. Am. J. Physiol., 242: G435 (1982).

25. Shepherd, A.: Effect of arterial pulse pressure and hypoxia on myogenic responses in the gut. Am. J. Physiol., 235: H157 (1978).

26. Shepherd, A., Pawlik. W.. Mailman. D., Burks, T., and Jacobsen, E.: Effect of vasoconstrictors on intestinal vascular resistance and oxygen extraction. Am. J. Physiol., 230: 298 (1976).

27. Siregar, $H$. and Chou, C.: Relative contribution of fat, protein, carbohydrate and ethanol to intestinal hyperemia. Am. J. Physiol., 242: G27 (1982).

28. Svanik, J.: Mucosal hemodynamics in the small intestine of the cat during regional sympathetic vasoconstrictor activation. Acta Physiol. Scand., 89: 19 (1973).

29. Svanik, J., Tyllstrom, J., and Wallentin, I.: The effects of hyperemia and hypoxia on the distribution of capillary blood flow in the denervated intestinal vascular bed. Acta Physiol. Scand., 74: 543 (1968).

30. Vatner, S., Higgens, C.. and Franklin, D.: Regional circulatory adjustments to moderate and severe chronic anemia in conscious dogs at rest and during exercise. Circ. Res., 30: 731 (1972).

31. Wallenstein, S., Zucker, C.. and Fleiss, J.: Some statistical methods useful in circulation research. Circ. Res., 47: 1 (1980).

32. Recipient of Basil O'Connor Starter Research Grant (\#5-256) from the March of Dimes Birth Defect Foundation.

33. The authors thank Mr. Raymond Petit for his skillful technical assistance; Albert S. Most, MD, FACC, Physician in Charge, Division of Cardiology and the staff of the Cardiovascular Research Laboratory, Rhode Island Hospital, for their assistance and cooperation; and Ms. Brenda Swanson for her secretarial assistance.

34. Requests for reprints should be addressed to: William Oh, MD, 50 Maude Street, Providence, RI 02908

35. This research was supported by National Research Service Award \#1 T32 HD07232-01.

36. Received for publication October 22, 1982.

37. Accepted for publication July 14, 1983 .

\title{
Relative Efficacy of Radiant and Convective Heat in Incubators in Producing Thermoneutrality for the Premature
}

\author{
MICHAEL H. LEBLANC(27) \\ University of Cincinnati College of Medicine and The Children's Hospital Research Foundation, \\ Cincinnati, Ohio, USA
}

\begin{abstract}
Summary
To determine which warming system more closely approximates a neutral thermal environment, the oxygen consumptions of 16 premature babies $<1500 \mathrm{~g}$ were measured in a convectively heated incubator and a radiantly heated incubator. Both systems were controlled to maintain a skin temperature of $36^{\circ} \mathrm{C}$. The oxygen consumptions of the infants were not significantly different in the two incubators; thus, there was no detectable advantage to the use of convective or radiant energy in approximating a neutral thermal environment in an incubator for the small premature infant. That proportion of total heat loss from the babies due to radiant losses in the convective incubator was directly calculated from incubator temperature using equations described in the paper, and found to be $68 \pm 3 \% \mathrm{SE}$.
\end{abstract}

A neutral thermal environment is an environment in which standard metabolic rate, or oxygen consumption, is minimal, and within which temperature regulation is achieved by nonevaporative physical processes alone (2). Because the neutral thermal range (21) seems to coincide with the conditions under which premature babies show the greatest survival rate $(4,7)$, it has been theorized that the best incubator or warmer would be one which maintained the infant in a neutral thermal environment: a state of minimal oxygen consumption.

The survival rate studies by Day et al. (7) and Buetow and Klein (4) showed that the highest survival rate was achieved in a warm radiantly heated incubator. Because this radiantly heated incubator is no longer manufactured, most nurseries use convectively heated incubators or open radiant warmers. Equally warm radiantly and convectively heated enclosed incubators have never been compared, either for survival rate or for thermoneutrality. But it was demonstrated in our laboratory that the open radiant warmer is less thermoneutral for the small premature than a convectively heated incubator (12). The radiant incubator, in contrast to the open radiant warmer, has a more consistent air flow pattern as it is enclosed rather than open. It has a warmer air temperature and, thus, less difference between effective radiant and convective temperature. The relative inferiority of the thermal environment produced by an open radiant warmer may or may not be due to the use of radiant energy as a heat source. It seemed appropriate, therefore, to compare infants' oxygen consumptions in a radiantly heated incubator and a convectively heated incubator.

\section{MATERIALS AND METHODS}

Sixteen infants under $1500 \mathrm{~g}$ were studied. The 16 infants were feeding and gaining weight at the time of the study and required no supplemental oxygen. Informed consent was obtained. A summary of the characteristics of the infants is given in Table 1.

Each infant was studied both in the radiantly heated incubator and the convectively heated incubator. The order in which the incubators were used was randomized. The infant's oxygen consumption was measured during a period of non-REM sleep after the infant equilibrated at least $1 \mathrm{~h}$ in each of the incubators. Non-REM sleep was defined as a period of $20 \mathrm{~min}$ of apparent sleep with a period of at least $10 \mathrm{~min}$ of regular respirations, no rapid eye movements (by observation through closed lids), and no gross movements except occasional jerks. All oxygen con- 